\title{
REDUCING DISPARITIES WITHIN A REGION: NEW APPROACHES FOR IDENTIFYING AND ELIMINATING DISPARITIES IN AIR POLLUTION IN SAN FRANCISCO BAY AREA COMMUNITIES
}

\author{
JACK P. BROADBENT \\ Bay Area Air Quality Management District, USA
}

\begin{abstract}
The San Francisco Bay Area in California is home to over 7 million people, many of whom live in communities that experience elevated levels of toxic air contaminants due to their relative proximity to industrial and mobile sources of air pollution. The Bay Area Air Quality Management District (Air District), the regional air pollution control agency delegated to govern for the San Francisco Bay Area, has been working to reduce these toxic air contaminant levels over the past decade through the implementation of our Community Air Risk Evaluation (CARE) program. The CARE program is our framework for identifying areas within the region with worse-than-average air quality impacts. It combines science-based analysis of air quality disparities and a more collaborative style of community engagement. It has been used to establish targeted incentive programs and expanded stationary source regulations that strive to reduce health risks for our most socioeconomically vulnerable populations. The Air District is now embarking on a renewed effort to eliminate these risks by incorporating more recent air quality and population data into our analysis, by using new provisional strategies to enhance monitoring and modeling, by targeting regulations for large industrial sources of toxic air contaminants and creating additional incentives to clean up mobile sources of diesel particulate matter. This article describes these past and ongoing efforts and specific measures being taken to ultimately eliminate disparities in air pollution in the Bay Area.
\end{abstract}

Keywords: air, quality, control, communities, management, plan, strategy, local, sub-regional, disparity.

\section{INTRODUCTION}

Air quality in the San Francisco Bay Area of California has significantly improved over the past several decades. This improvement is due to the increasingly stringent emission control standards at the local, regional, state, and federal level for stationary, mobile and area sources of air pollution. The progress has occurred even while the region's population and vehicle miles travelled have increased. Figs 1 and 2 illustrate two key trends: the reduction in our regionwide ozone and particulate matter (PM) concentrations.

Despite tremendous strides in regional air pollution reduction in the region, some communities still experience relatively higher pollution levels and corresponding health effects. These disparities in air pollution are highest in close proximity to significant pollution sources such as near freeways, busy roadways, trucking and distribution centers, and large industrial facilities.

To address these problems, the Bay Area Air Quality Management District (Air District) has created our Community Air Risk Evaluation (CARE) program. This program has been our platform for creating targeted grant incentive programs and new or revised stationary source regulations that can reduce air pollution in our "CARE areas." Recent state legislation has reinforced and extended these efforts with new community risk-based policy and administrative funding. This new State programme is enabling the Air District to expand our community-scale monitoring networks and to develop community-engaged action plans for 


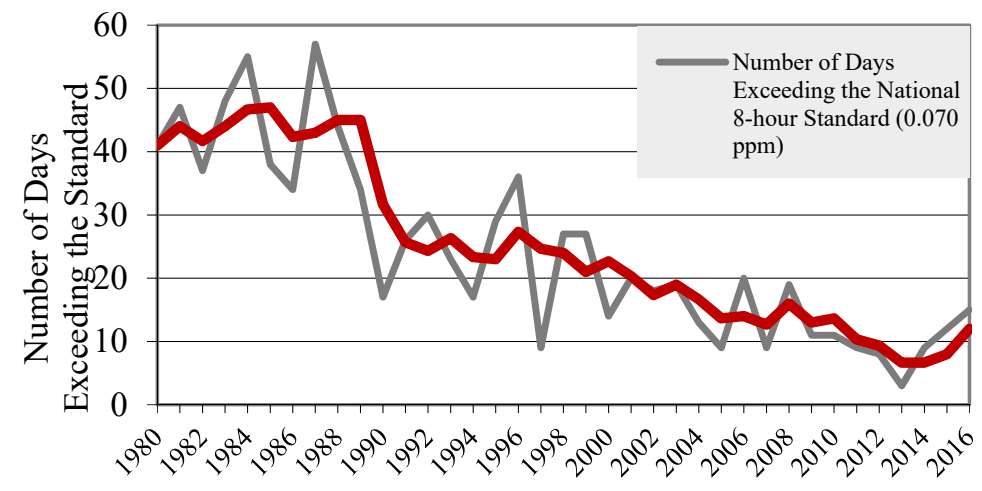

Figure 1: Annual Bay Area days exceeding $0.07 \mathrm{ppm}$ National 8-hour Ozone standard at any monitoring station, 1980-2016.

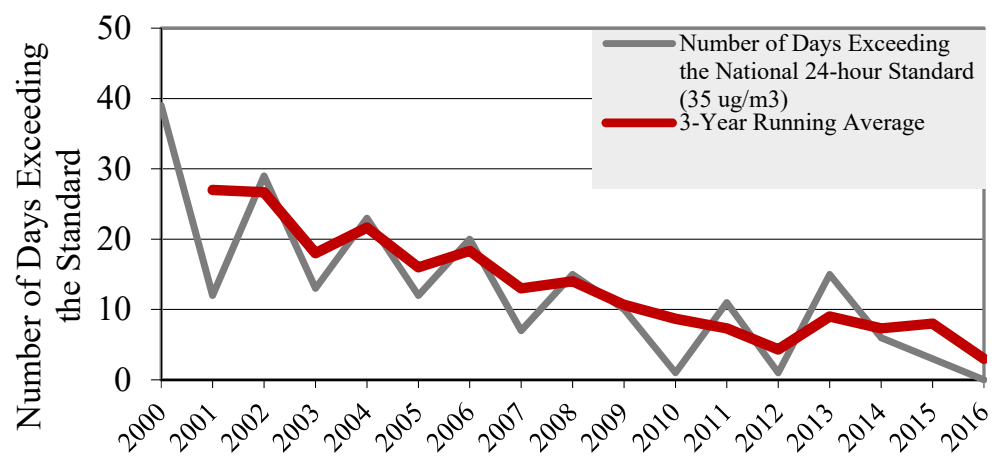

Figure 2: Annual Bay Area days exceeding $35 \mu \mathrm{g} / \mathrm{m}^{3}$ National 24-hour PM standard at any monitoring site, 2000-2016.

addressing pockets of depressed air quality. The purpose of this paper is to describe the CARE framework that the Air District created to identify sub-regional pockets of disparate air quality and to offer case studies of efforts undertaken in conjunction with the CARE framework. The goal of this paper is to explore the tools and strategies that a regional air pollution control agency might use to look beyond regional averages to reduce disparities in air quality exposure and associated health effects.

\section{BAY AREA AIR QUALITY MANAGEMENT DISTRICT}

The Air District serves as the local air pollution control agency for the nine-county region of the San Francisco Bay Area in California. It was established in 1955 and is comprised of approximately 380 staff and a board of 24 local elected leaders. The Air District is an independent agency created under state law. It has been delegated authority to implement the federal and state clean air acts. The mission of the District is to protect and improve public health, air quality and the global climate. 
The Air District is primarily responsible for regulating industrial stationary sources. It has developed and currently enforces a comprehensive programme to limit emissions from over 10,000 facilities. The programme covers from our smallest sources (e.g., gas stations, household paint, residential water heaters and commercial back-up generators) up to the largest sources (e.g., chemical plants, cement production facilities, power-generating stations and petroleum refineries). Although the regulatory programme for these courses is generally considered the most stringent in the US, the Air District relies on complementary outreach and incentive programmes to achieve our air quality and climate stabilization goals.

The Air District maintains thirty-one permanent air monitoring stations that continuously collect and report air quality information for the region (Fig. 3). Each of these monitoring stations measures some of the following pollutants: ozone, PM, ultra-fine PM, lead, nitrogen oxide, Sulphur dioxide, carbon monoxide, black carbon, Toxic Air Contaminants (TACs), hydrogen sulfide and GHGs. A few air monitors collect lead and two background sites collect upwind and downwind concentrations of GHGs. The focus in this paper is our effort to develop our capacity beyond these stations to deploy portable and local, fixed monitors to enable sub-regional monitoring at the community scale. Our CARE programme is our first framework for doing so.

\section{COMMUNITY AIR RISK EVALUATION (CARE) PROGRAM}

The Air District first initiated a comprehensive program to address regional disparities in air pollution exposure and health effects over a decade ago. We named this our CARE Programme and have used it to designate areas within the Bay Area where air pollution is most contributing to negative health impacts and where populations are most vulnerable to air pollution impacts.

The programme uses science-based air quality measurements and analysis to map areas of disparate air pollution and to characterize the sources of air pollution within them. We use these maps and characterizations to engage stakeholder groups and local agencies to explore mitigation efforts and to extend the range of strategies beyond what the Air District could do alone. It is within this framework that we have worked to designate impacted communities, to create target grand and incentive programs, and to enhance our stationary source regulations. These efforts are described in the next sections and then explored using case studies from the West Oakland neighborhood, a geography of disparate air quality that we have designated and engages as a CARE area.

\section{DESIGNATING IMPACTED COMMUNITIES}

To enable our CARE efforts, the Air District needed a methodology that could help us differentiate air quality based-health risks in the Bay Area. We developed a methodology that we call the Pollution Vulnerability Index (PVI). The PVI is our bases for seeing an air quality depression within our region and for designating it as a CARE area. Fig. 4 illustrates the types of data that we aggregate to create and map the PVI.

The first of these data are types of air pollution. To help us assess incremental cancer risk, we aggregate geographically-based emissions data for toxic air contaminants (TACs). To help us assess mortality and morbidity impacts, we aggregate exposure data for particulate matter (PM), and for ozone $\left(\mathrm{O}_{3}\right)$. Since ozone modeling was only available for a few time periods and since ozone concentrations change more gradually from one location to another than $\mathrm{PM}_{2.5}$ concentrations, using measurements only was found to produce more realistic results for predicting mean 8 -hour ozone levels than using a combination of modeling and measurements. 


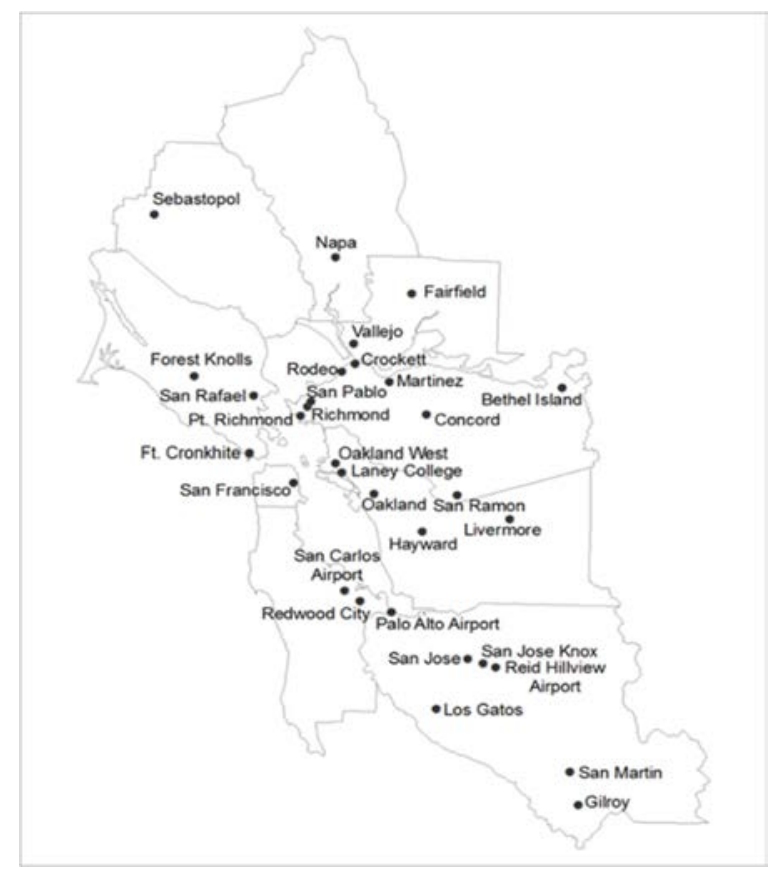

Figure 3: 2017 Air monitoring network.

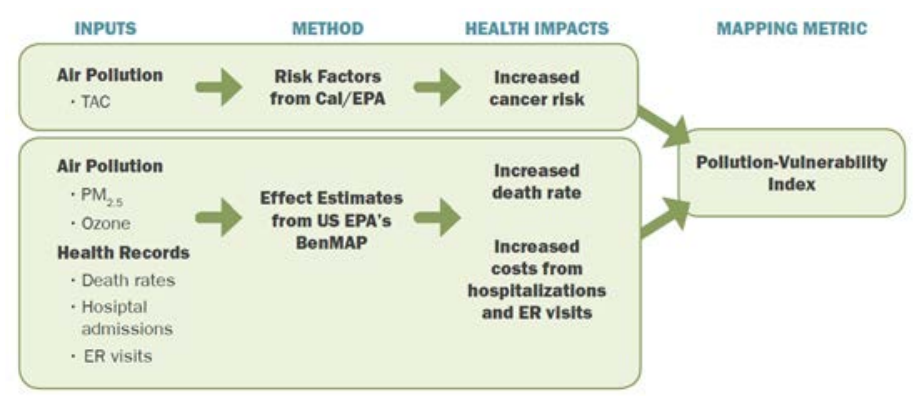

Figure 4: Schematic representation of CARE methodology.

We used the U.S. EPA's BenMAP model [1] to predict health impacts based on pollution levels above regional measurements using data from local health records including mortality rates, emergency room visits, and hospitalizations related to respiratory and cardiovascular diseases (i.e. asthma, pneumonia, COPD, other respiratory diseases, heart attack, and other cardiovascular diseases) aggravated by air pollution. Baseline rates were age-adjusted, meaning that age difference between one community and another were not a factor in determining vulnerability. Alternatives to applying age-adjustments will be explored in future work. We use the combination of potential cancer risk and health impacts from fine PM and ozone to form the PVI. Because health records are available by zip code, the PVI can be mapped to areas based on zip codes (Fig. 5). 


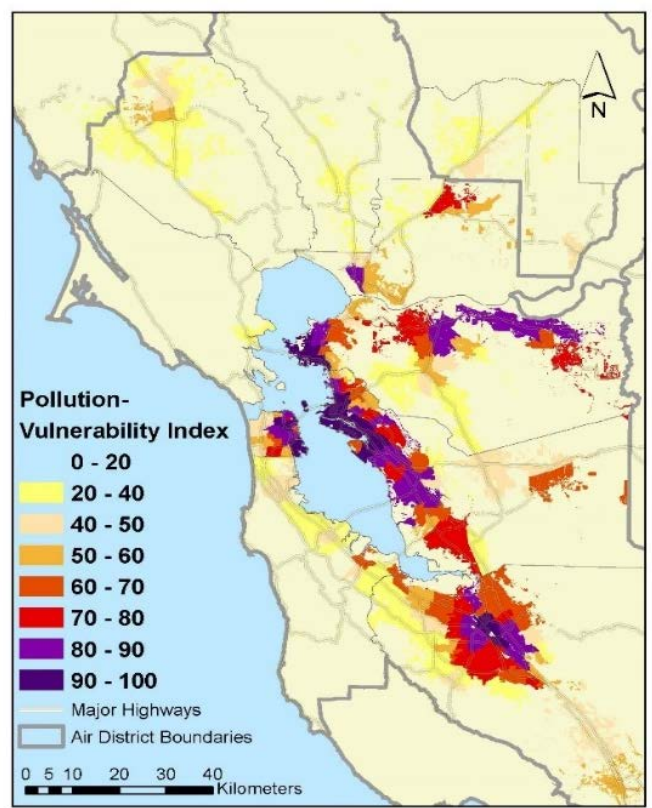

Figure 5: The pollution-vulnerability index uses information on air pollution levels and health outcomes for each zip code area.

TAC emissions are high in the urban core of the Bay Area. PM concentrations are also high in these areas. Some PM is formed in the atmosphere from other pollutants, it also tends to be high downwind from the highest emissions sources. Ozone concentrations are highest downwind of the significant emission sources because nearly all ozone is formed from other pollutants.

The map in Fig. 5 shows PVI values in populated portions of each zip code throughout the Bay Area. A low value of the PVI corresponds to lower health impacts; a high value corresponds to higher health impacts. By considering existing rates of mortality and illnesses when determining health impacts from fine PM and ozone, in addition to the levels of these pollutants, population vulnerability was accounted for in the PVI. The highest PVI values occur where TAC and PM concentrations are high and where health records indicate higher rates of illness associated with air pollutants.

\section{AIR DISTRICT ACTIONS TO BUILD HEALTHY COMMUNITIES}

One of the main goals of the CARE program has been not only to identify impacted communities but to help design and focus effective air pollution mitigation measures that would be implemented by local, regional, state and federal organizations. To carry out actions to improve air quality and reduce health impacts by the Air District, a coordinated strategy that uses many of the Air District's available resources has been deployed.

Fig. 6 illustrates that communities identified through the CARE program are being integrated into all Air District's programs and inform a broad array of actions designed to foster healthy communities. 


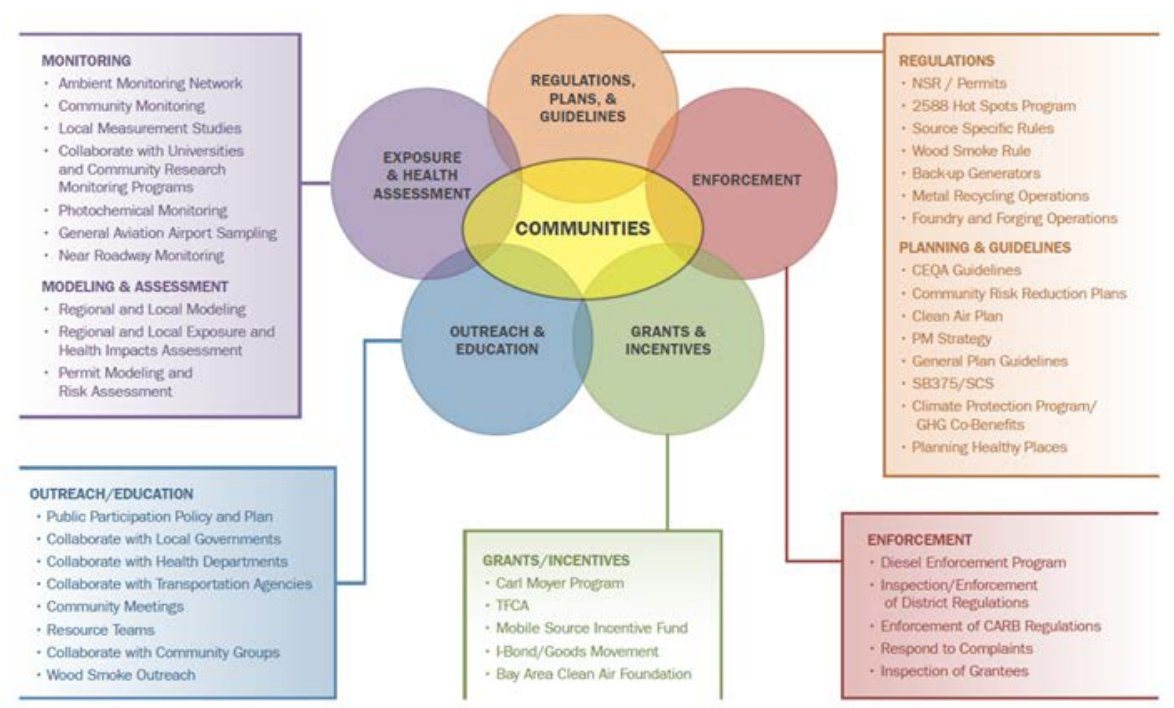

Figure 6: The Clean Air Communities Initiative integrates consideration of impacted communities into many Air District programs.

\section{TARGETED GRANTS AND INCENTIVES}

Since 1992, the Air District has awarded over $\$ 700$ million in grant funds for cost effective emission reduction projects. The Air District's grants are used to retrofit and replace older diesel on-road trucks, construction equipment, school buses, trains, cargo-handling equipment, ships, and to install electric vehicle recharging stations. These grants have been instrumental in reducing air pollution emissions and health risks throughout the Bay Area, particularly along transportation corridors. Mobile sources such as trains, trucks, ship and construction equipment are targeted by these grants as fleets of these sources typically have a lower rate of turn-over and are often located in impacted communities.

The purpose to the grant programs is to expedite reductions in mobile source emissions through the distribution of incentive funds to purchase lower and zero-emission equipment for public agencies, school districts, and private companies. Air District's grant programs complement and enhance CARB mobile source regulations by supporting emission reduction projects that exceed CARB requirements. The Air District's primary funding programs include the Transportation Fund for Clean Air, Mobile Source Incentive Fund, Carl Moyer Program, Lower Emission School Bus Program, and Goods Movement Programme [2]. Funds for these programs are generated through surcharges on motor vehicle registration, tire fees, bond sales, and smog check fees.

In West Oakland, the Air District has provided significant funding to reduce emission over the past 10 years, including $\$ 33$ million in grant funding to initially retrofit 1,319 trucks and to subsequently replace an additional 627 trucks and $\$ 24.5$ million to install shore side power at 15 berths at the Port of Oakland.

The Air District targets its grant funding to reduce mobile source emissions in the region's most impacted communities. In 2016 more than $\$ 38$ million in grant funding was awarded to projects in impacted communities, representing more than $62 \%$ of the funds awarded that year. In 2018, the Air District will continue to prioritize a significant portion of its 
approximately $\$ 58$ million in grant funding on projects that improve air quality in the region's most impacted communities. In addition, the District will be distributing an additional $\$ 50$ million that was authorized though $\mathrm{AB} 134$ that will be entirely be focused reducing mobile source emissions in the region's most impacted communities.

\section{ENHANCED STATIONARY SOURCE REGULATIONS}

The Air District has adopted several regulations that target sources that contribute to local concentrations of toxic air contaminants in impacted communities. Three regulations in particular are described below.

\subsection{Metal recycling and metal melting}

A number of impacted communities in the Bay Area are impacted by metal recycling and shredding operations while others are impacted by metal melting facilities and forges. The Air District has adopted and enforces regulations on all of these types of facilities. The rule on metal recycling and shredding operations (Regulation 6, Rule 4) requires that facilities develop and implement plans to minimize fugitive PM emissions. Each plan is tailored to the unique design of the facility. The rule on foundries and forges (Regulation 12, Rule 13) requires plans to minimize emissions of PM and odorous compounds.

\subsection{Wood burning devices}

One of the Air District's major recent successes, the wood burning rule (Regulation 6, Rule 3 ), which prohibits use of wood-burning devices, such as fireplaces and woodstoves, when air quality is forecasted to be unhealthy from November through February. The rule has resulted in significant reductions in wintertime $\mathrm{PM}_{2.5}$ concentrations. Locally-emitted wood smoke accounts for approximately one-third of $\mathrm{PM}_{2.5}$ levels on days when Bay Area PM levels exceed the national 24-hr $\mathrm{PM}_{2.5}$ standard. Preliminary analyses suggest that the wood burning rule has reduced ambient wood smoke levels by 50 to $75 \%$. Wood burning devices are located throughout the Bay Area, both within and outside impacted areas. However, elevated PM levels are a main contributor to health impacts in CARE communities. By lowering PM levels throughout the region, this rule plays an important role in improving health in impacted areas. Because of the importance of reducing PM levels to improving health outcomes, Air District staff is currently investigating additional PM rules to reduce local impacts of particulate sources, many of which are located in CARE communities.

\subsection{Toxic air contaminants from industrial sources}

One of the most important regulations adopted by the Air District to address local exposure of toxic air contaminants from industrial facilities is Regulation 11 Rule 18: Reduction of Risk from Air Toxic Emissions at Existing Facilities (Rule 11-18 or "Toxic Risk Reduction Rule"). This regulation was adopted by the Board in November of 2017.

Rule 11-18 would apply to all facilities whose emissions of toxic air contaminants may result in a significant risk to nearby residents and workers. The purpose of this regulation is to focus on those facilities causing the highest health impacts across the Bay Area and to require these facilities to reduce that health risk.

Rule 11-18 is the next step in the Air District's efforts to protect public health from toxic air pollution. The rule is expected to substantially reduce health risks posed by various facilities by requiring the implementation of all technically and economically feasible risk reduction measures to significant sources of toxic air contaminants (TACs). The proposed 
rule would affect approximately 400 facilities, individual facilities such as petroleum refineries to much smaller businesses such as dry cleaners and crematoriums. These facilities emit a variety of TACs that can adversely impact public health. These pollutants include compounds such as diesel particulate matter (DPM), benzene, polycyclic aromatic hydrocarbons (PAHs), and 1,3-butadiene.

Under Rule 11-18, Air District staff will conduct Health Risk Assessment based on emissions estimates of toxic air contaminants from the affected facilities. These health evaluations would use the latest emission estimates available and, because they would be performed by the Air District, would use a process that is both consistent and transparent. During the risk evaluation process, the public would be allowed to review and provide input on the HRAs before they are finalized.

Any facility shown by a final HRA to pose a health risk at or above the risk action level in the rule would be required to take further steps to reduce risk. The risk action levels are tiered, starting at 25 per million upon rule adoption and dropping to 10 per million in 2020 , to ensure that high risk facilities are addressed first and can begin risk reduction efforts as soon as possible.

Facilities with risk at or above the action level would be required to develop a risk reduction plan to reduce risk below the risk action level of 10 per million within five years, if that timeline is feasible. If a facility can reduce their emissions below the risk action level, but technical or financial considerations make more time necessary, the Air District would be able to approve additional time, but no more than is needed, up to an additional five years. If it is not feasible for a facility to reduce its risk below the required levels, the rule provides a third option that would require the facility to install the best available retrofit control technology for toxics (TBARCT) on all significant sources of toxic emissions, thereby reducing risk to the lowest level feasible.

After plan approval, the facility would be required to implement the risk reduction measures and comply with all other requirements in the plan. Facilities would be required to report annually on progress. If new information becomes available about risk or about the feasibility of a plan, the rule provides a mechanism for updating the plan.

\section{LOCAL AIR QUALITY IMPROVEMENT: WEST OAKLAND CASE STUDIES}

Several efforts have been undertaken to characterize and understand the improvements in air quality taking place in local communities as a result of the above described actions by the Air District and others. Three local assessments in West Oakland, the most polluted community in the Bay Area, are described below.

\subsection{West Oakland health risk assessment}

Beginning in 2006, the Air District in collaboration with CARB and the Port of Oakland conducted a Health Risk Assessment [3] to estimate public health risk exposure from diesel PM emissions in West Oakland. Diesel exhaust emissions from maritime, railroad and on and off road mobile sources were quantified, and cancer risks estimated using US EPA's CALPUFF dispersion modeling. 2005 emissions estimates were utilized to establish a baseline.

The study concluded that back in 2005, the West Oakland community was exposed to diesel PM ambient concentrations that were almost three times higher than the average background diesel PM levels in the Bay Area. The estimated lifetime cancer risk for residents of West Oakland from exposure to diesel PM levels was about 1200 excess cancer per million 
over a 70-year lifespan. The study also found that the largest contributor to diesel PM were from on road heavy duty trucks in the West Oakland community.

Since this time, cancer risks have been reduced significantly due to the implementation of several emission reduction strategies by the Air District, CARB, and the Port of Oakland. Investments in cleaner on and off road heavy duty trucks, shore side electrification and other strategies have lowered ambient concentrations of diesel PM in West Oakland as documented in studies described below.

\subsection{Drayage truck plume assessment}

While studies were underway that characterized health impacts from diesel emission in West Oakland, mitigation strategies were being deployed to address these impacts. Among these strategies, was a statewide regulation on drayage truck emissions from CARB which took effect in 2010 [4]. As a result of this measure, all drayage trucks were required to meet 2007 engine emissions standards.

In order to understand the effectiveness of this strategy, the Air District help fund a study designed and conducted by the University of California at Berkeley and the Lawrence Berkeley National Laboratory. These researchers measure drayage truck emissions near Port operations before and after the implementation of the CARB regulation. These researchers found that ambient concentrations of diesel PM decreased by $50 \%$ and NOx by $40 \%$.

\subsection{West Oakland monitoring study}

The Air District partnered with the Desert Research Institute (DRI) to conduct the West Oakland Monitoring Study (WOMS) [5]. WOMS provided supplemental air quality monitoring data (Fig. 7) to identify potential air pollution hot spots in West Oakland and to evaluate local-scale dispersion modeling of diesel emissions from the Port of Oakland and vicinity.

The WOMS study taken in combination with other recent studies indicates that focused grants-funded diesel reduction projects, new regulatory requirements, and focused enforcement near the Port of Oakland have been effective. However, the study also showered higher pollutant concentrations along major roadways in West Oakland, especially in areas with high traffic volumes of diesel trucks.

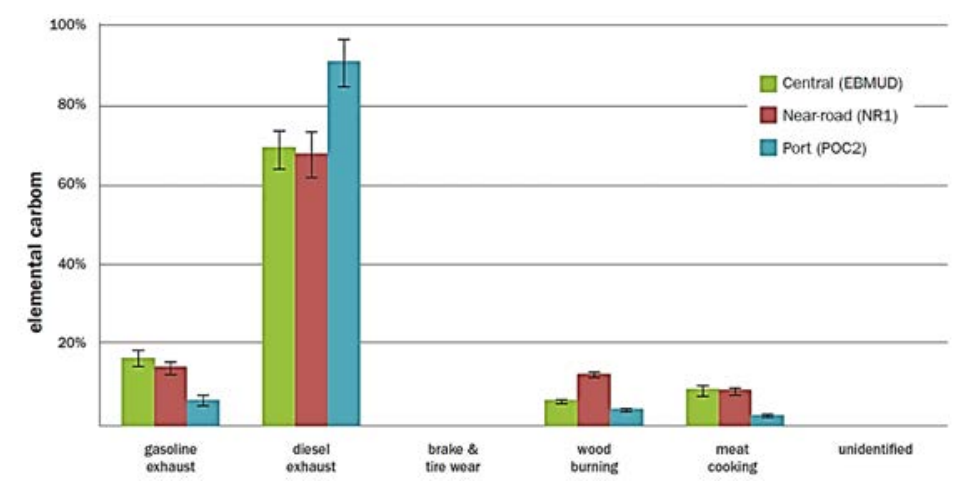

Figure 7: Estimates of source contributions to ambient elemental carbon by Chemical Mass, Balance during winter 2009-2010 in West Oakland. 


\section{AB 617: THE CALIFORNIA COMMUNITY PROTECTION PROGRAM}

AB 617 established a new community focused action program to improve air quality and reduce exposure to criteria air pollutants and toxic air contaminants in communities most impacted by air pollution. This law requires the Air District working in coordination with CARB to identify and select communities with the highest cumulative exposure burdens, develop and deploy neighborhood scale air monitoring networks to characterize population exposure, and develop and deploy community-based emission reduction plans to reduce exposure.

At present, the Air District is in the process of seeking input to formally identify the communities that will fall subject to this process. The Air District plans to rely on the results of the CARE program, input from communities as well as key relevant factors such as local health data to identify impacted communities.

\section{KEY POLICY CONSIDERATIONS}

The implantation of $\mathrm{AB} 617$ presents several challenges and opportunities for the Bay Area. Key policy considerations for this effort include the lack of local community capacity in some areas of the Bay Area, which air monitoring approaches and emissions reduction measures to deploy, and how to measure success of local community plans.

\subsection{Community capacity}

Several communities in the Bay Area lack community organizations or expertise to local sources that may be contributing to air pollution in their neighborhoods. The Air District plans to work with local communities and provide resources to local organizations to help in deploying monitors, establishing potential emissions reduction strategies and disseminating information on health impacts and improvements.

\subsection{Air monitoring approaches}

As shown in Fig. 3, the Air District currently operates an extensive ambient air monitoring network for the Bay Area. This network however, may not fully capture the fine scale local concentrations of various toxic air contaminants that some communities experience. This microscale assessment of neighborhoods will take time and resources to deploy dense monitoring networks. Which pollutant to be monitored will be an important consideration moving forward. The cost of PM monitoring has become increasingly cost effective, but in some neighborhoods, monitoring approaches will need to evaluate whether air toxics are present. The Air District plans to rely on stationary and mobile source emissions inventory estimates and input provided by community organizations in deploying monitoring efforts.

\subsection{Emission reduction strategies}

Ultimately, the Air District working with representatives from community groups, cities, counties, other regional governmental organizations, the state and federal government, will need to develop a set of mitigation strategies that can reduce local ambient concentrations of air pollutants of concern. Strategies will include but not be limited to: additional grant incentive programs to further reduce diesel emissions sources, rerouting truck routes in neighborhoods, anti-idling measures and additional stationary source regulations on smaller neighborhood sources.

An important strategy that will need to be considered is how to address new smaller neighborhood stationary sources that are continually being proposed in communities. While 
such sources, such as dry cleaners, gas stations and crematoriums are designed and built with the most stringent controls, they collectively add to the cumulative air pollution burden in communities throughout the Bay Area.

\subsection{Measuring success}

The successful implementation of community emissions reduction plans will require the development of metrics in measuring success of these plans. Key factors the Air District plans to rely on include, emissions inventory estimates, ambient air quality measurements and related health information. The Air District plans to work with community groups to define these metrics through an open and transparent process.

\section{ACKNOWLEDGEMENTS}

The author would like to acknowledge Areana Flores for her tireless effort in assisting in the development of this paper. The author also wishes to acknowledge the following for their contribution to the paper: Dr. Phil Martien, Dr. Chad White, Karen Schkolnick and Victor Douglas.

\section{REFERENCES}

[1] United States Environmental Protection Agency, Environmental Benefits Mapping and Analysis Program, www.epa.gov/benmap/. Accessed on: 13 Feb. 2018.

[2] Bay Area Air Quality Management District, Grant Funding, www.baaqmd.gov/ Divisions/Strategic-Incentives.aspx. Accessed on: 22 Jan. 2018.

[3] Di, P., Diesel Particulate Matter Health Risk Assessment for the West Oakland Community 2008. California Air Resources Board: California, US, 2008 [cited Dec. 2010]. p. 48. www.arb.ca.gov/ch/communities/ra/westoakland/westoakland.htm.

[4] California Air Resources Board, Drayage Truck Regulatory Activities, www.arb.ca.gov/msprog/onroad/porttruck/porttruck.htm. Accessed on: 22 Jan. 2018.

[5] Fujita, E.M. \& Campbell, D.E., West Oakland Monitoring Study 2010. Desert Research Institute: Nevada, US, 2010 [cited 1 Oct. 2010]. p. 115. www.baaqmd.gov/plans-andclimate/community-air-risk-evaluation-care-program/documents. 